\title{
FOREIGN OBJECT DAMAGE ISSUED BY INDUSTRY 4.0
}

\author{
Martin Melichar* \& Nikola Skřivanová
}
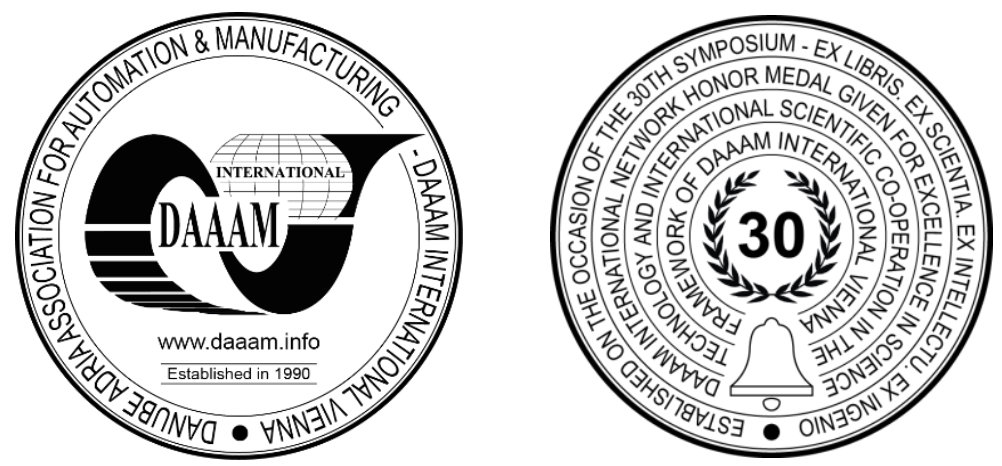

This Publication has to be referred as: Melichar, M[artin] \& Skrivanova, N[ikola] (2020). Foreign Object Damage Issued by Industry 4.0, Proceedings of the 31st DAAAM International Symposium, pp.0202-0208, B. Katalinic (Ed.), Published by DAAAM International, ISBN 978-3-902734-29-7, ISSN 1726-9679, Vienna, Austria DOI: $10.2507 / 31$ st.daaam.proceedings.027

\begin{abstract}
In the field of aerospace inspection, the prevention of damage caused by foreign objects is a very serious topic, as in the past the FOD has caused a number of accidents. The FOD itself can be divided into many types but this article deals with foreign objects that are bound to components during the production process. Detection of foreign objects is one of the key tasks of inspection and is also mentioned in the international aerospace standard EN9100 / AS9100. During the experiment, the results of FOD detection were experimentally compared by visual inspection by the operator in 3 shifts and a robotic workplace with the same task. The article deals with the practical implementation and evaluation of the influence of human labour compensation on the RPN parameter used to determine the riskiness of the process according to the PFMEA methodology. The article describes the PFMEA methodology, in the experimental phase describes and analyses the inputs and outputs of the PFMEA methodology in a real environment.
\end{abstract}

Keywords: Aerospace; FOD; industry 4.0, PFMEA, Inspection

\section{Introduction}

\subsection{Introduction - general}

This article deals with the critical point of inspection of aircraft components - FOD. Like all processes, FOD-related inspections have been and are being handled manually within the process and final inspection departments, which carries with it the usual limits associated with human involvement. The aim of the research carried out within the Regional Institute of Technology, University of West Bohemia in Pilsen, was to verify and quantify the possibility of deploying an automated control workplace on a specific aircraft component.

During the long-term study, a FOD inspection was performed to inspect the production batches of the SUMP product. This inspection and its results were subsequently revaluated and assessed in terms of time and process stability. These data were then summarized in a PFMEA study, which takes into account the risks of the inspection. The differences are clearly presented through the RPN risk number, which confirms or refutes the possibility of deploying an automatic FOD inspection instead of a manual inspection. 


\subsection{Introduction - Industry 4.0}

The fourth industrial revolution and Industry 4.0 are terms which denote today's trend toward digitization and automation of production. The first idea of Industry 4.0 emerged in 2011 as a vision of a smart factory relying on cyberphysical systems which substitute people in performing simple and monotonous tasks. In 2013, a framework for materialising this industrial concept was developed in Hannover. Its main attributes included machine perception, selfconfiguration and self-diagnosis. This means that machines can report breakdowns automatically, warehouses monitor their stock levels, and cloud storage is widely used, as is 3D printing and data centres. Every product and every machine are provided with their own microchip, and are therefore easy to track. As a result, most management and inspection tasks can be performed on-line via the internet. [6]

The key benefits include time savings, improved productivity and enterprise flexibility. The quality of life is thus expected to rise because repetitive, physically demanding and ineffective jobs, i.e. ineffective in terms of ergonomics, are gradually eliminated. Enhanced logistic operations and systems integration will deliver better efficiency and reduce environmental burden thanks to the use of renewable resources, such as solar power, and others..

On the other hand, not all effects are positive in this context. There will be a clear impact on the job market. Although new positions will emerge for highly-qualified personnel to manage the automation process, people who used to perform simple tasks will lose their jobs and will find it difficult to find employment. Other threats are associated with the operation of such systems - computer hacker attacks and misuse of data can be expected. [1], [3], [5]

\section{FOD}

\subsection{Foreign Object Damage - introduction}

FOD or Foreign Object Debris is s an important safety and quality control concept in any aviation, aerospace, manufacturing, warehouse, shipping, military or similar environment where small debris, loose objects, wildlife and even stray humans have the potential to cause:

- Damage to manufactured equipment

- Injury to employees, visitors or passengers

- Delays or safety violations

Foreign Object Damage is damage caused by Foreign Object Debris that compromises the quality, functionality or economic value of a manufactured item. For instance, a piece of FOD at the wrong place at the wrong time can:

- Shred fan blades when sucked into a turbojet

- Blow out tires at high speeds

- Damage delicate components when trapped inside of an equipment housing

- Freeze control mechanisms when lodged next to levers and handles

While hard numbers are difficult to come by, it has been estimated that FOD costs the civilian aviation sector between billions of dollars annually in damaged equipment, flight delays, reduced efficiency, litigation and other costs. FOD also has the potential to injure employees, passengers, factory workers and others. In addition, FOD in military environments can affect national security, reducing air defence and other mission capabilities.

\section{Case analysis}

\subsection{Final inspection case study}

This paper describes an assessment of automation of inspection using real-world data from a company which operates in the aerospace industry. The data comes from serial production of aluminium part. Two FOD inspection lines were compared. Both of them are currently used in the process. The one which has not been automated yet has been in operation for several years with minor improvements gradually introduced. One year ago, an automated line was installed next to it. In this new line, most operations which used to be performed by a worker/inspector are done by a robot. Even this automated line, though, requires the operator to carry out basic infeed and outfeed tasks. The automated line is monitored continuously and its processes are being refined. Such preparations may eventually lead to full automation.

The inspected products of both lines are SUMPs - internal parts of kitchen in the plane . They consist of the monolithic parts, a fasteners and tube, all made from aluminium. It should be pointed out that for the purposes of this paper, the SUMP is considered the final product, although this only applies to the inspection lines described here. These lines have to inspect specific (customer defied parameters) and the FOD as well. In this case FODs were defined as chips from machining and cutting fluid residues. [7], [1] 


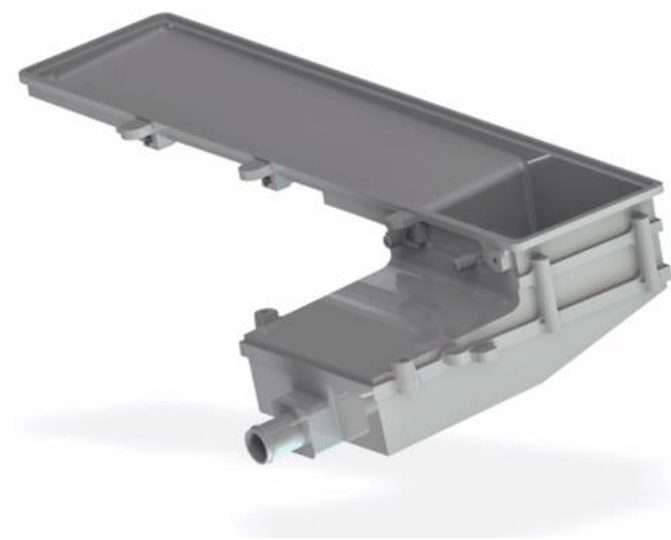

Fig. 1. SUMP part

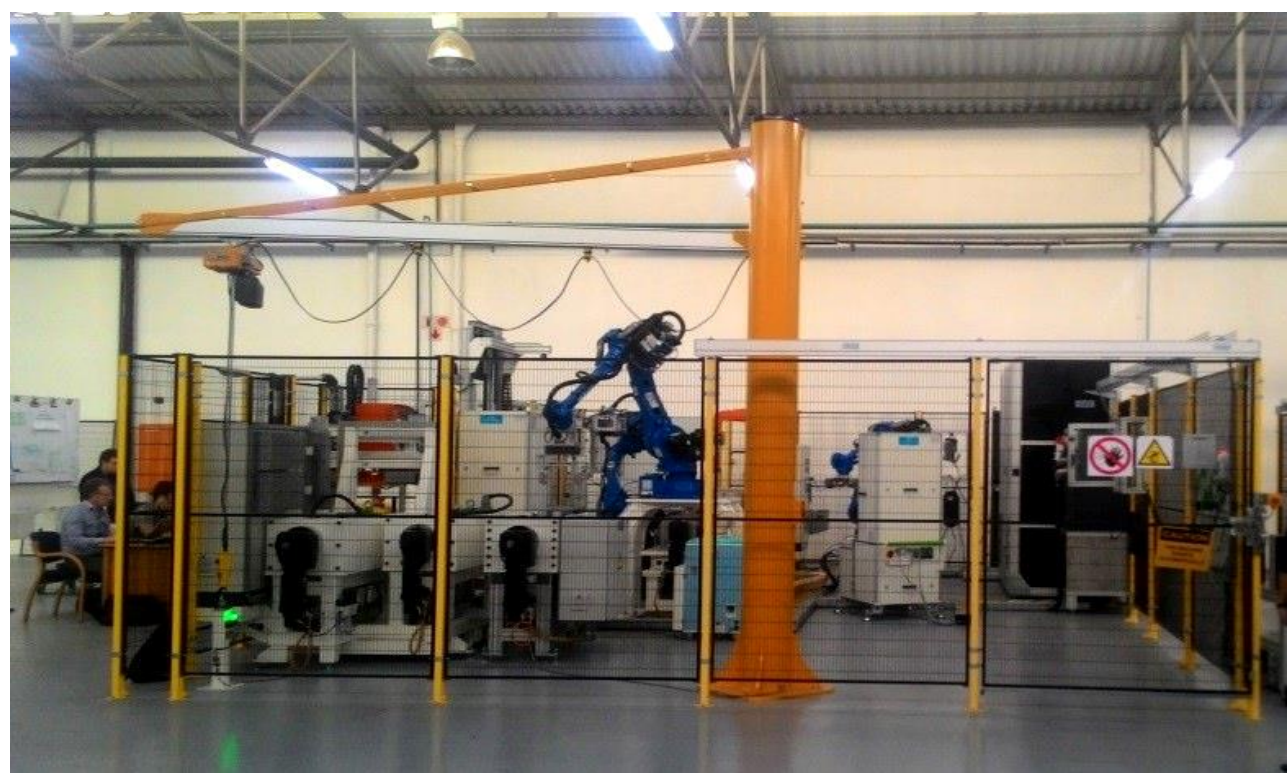

Fig. 2. Robotic inspection line

\section{Inspection of process stability}

In the paper, statistical process control (SPC) was used to find whether the inspection process is under control, whether the process location parameter $\mu$ can be estimated reliably by the median and whether variability can be characterized by the standard deviation value. The evaluation will be based on inspection times for individual SUMPs, from the first to the last inspection step. Data were gathered as groups: every measurement value is in fact an average value from a batch of 5 articles. This was applied to both the manual and the automated line. [8]

The table below lists the inspection times for a single canned catalysts on the manual line. Three rejects (marked as "R") were detected in the group of products of interest.

\begin{tabular}{|c|c|c|c|c|c|c|c|c|c|c|c|c|c|c|}
\hline Batch & $\mathbf{1}$ & $\mathbf{2}$ & $\mathbf{3}$ & $\mathbf{4}$ & $\mathbf{5}$ & $\mathbf{6}$ & $\mathbf{7}$ & $\mathbf{8}$ & $\mathbf{9}$ & $\mathbf{1 0}$ & $\mathbf{1 1}$ & $\mathbf{1 2}$ & $\mathbf{1 3}$ & $\mathbf{1 4}$ \\
\hline $\begin{array}{c}\text { Time } \\
\text { [sec] }\end{array}$ & 45,7 & 47,2 & 32,3 & $\boldsymbol{R}$ & 44,6 & $\boldsymbol{R}$ & 50,8 & 47,1 & 46,7 & 46,1 & 43,3 & 45,6 & 50,9 & 50,4 \\
\hline Batch & $\mathbf{1 5}$ & $\mathbf{1 6}$ & $\mathbf{1 7}$ & $\mathbf{1 8}$ & $\mathbf{1 9}$ & $\mathbf{2 0}$ & $\mathbf{2 1}$ & $\mathbf{2 2}$ & $\mathbf{2 3}$ & $\mathbf{2 4}$ & $\mathbf{2 5}$ & $\mathbf{2 6}$ & $\mathbf{2 7}$ & $\mathbf{2 8}$ \\
\hline $\begin{array}{c}\text { Time } \\
{[\mathbf{s e c}]}\end{array}$ & 46,7 & 48,1 & 49,8 & 47,8 & 45,8 & 49,1 & 45,9 & 46,3 & $\boldsymbol{R}$ & 47,4 & 46,6 & 46,6 & 46,3 & 50,9 \\
\hline
\end{tabular}

Table 1. Manual inspection line data

Using these data, standard deviation, median, frequencies of occurrence of individual times and other values were calculated for the purpose of creating histograms. The graph is shown below. 


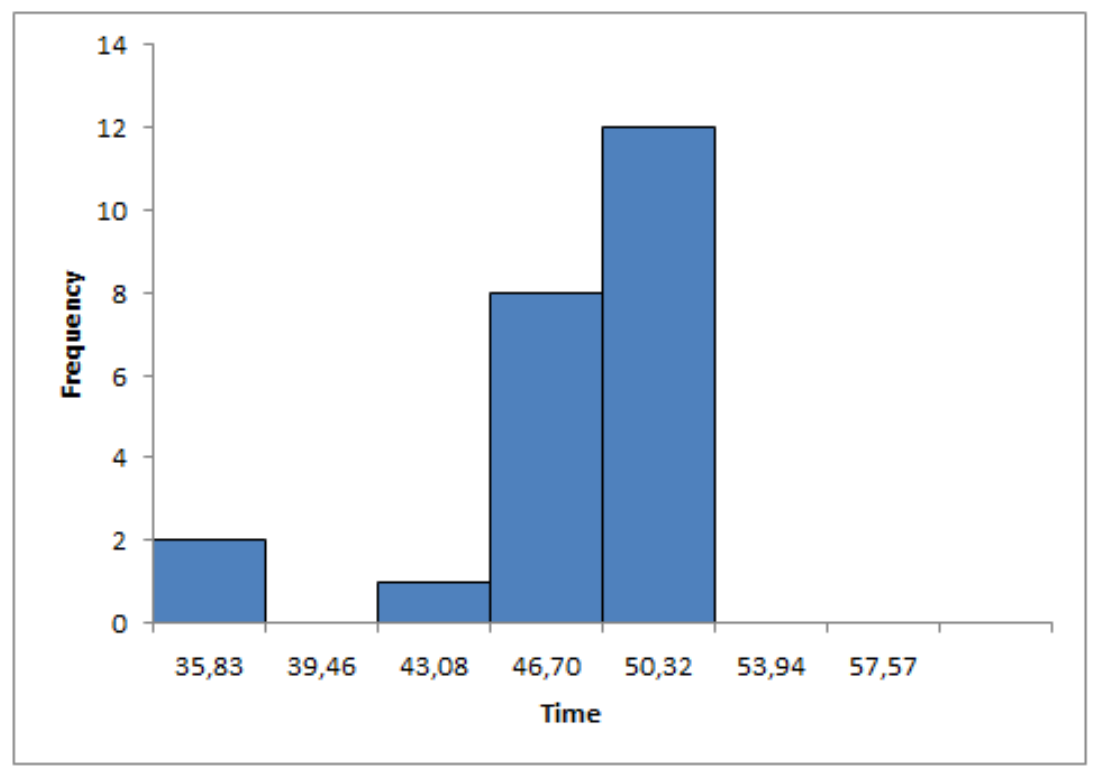

Fig. 3. Histogram, Frequencies on manual line

The data are completely disordered and clearly do not follow the desired normal distribution. As mentioned above, the manual line is not the main inspection plant for SUMPs any more. It is only used upon customer's specific request, provided that the desired output volume is small. [7]

The automated inspection line checks most of the outputs under strict time and other requirements. The table below lists measured data which were collected using the same procedure as with the manual line. It is clear at first sight that the error rate in this line is lower. In the remeasuring run, there was only one reject.

\begin{tabular}{|c|c|c|c|c|c|c|c|c|c|c|c|c|c|}
\hline Batch & $\mathbf{1}$ & $\mathbf{2}$ & $\mathbf{3}$ & $\mathbf{4}$ & $\mathbf{5}$ & $\mathbf{6}$ & $\mathbf{7}$ & $\mathbf{8}$ & $\mathbf{9}$ & $\mathbf{1 0}$ & $\mathbf{1 1}$ & $\mathbf{1 2}$ & $\mathbf{1 3}$ \\
\hline Time [sec] & 30,8 & 30,7 & 27,8 & 30,7 & 24 & 29,7 & 29,4 & 30,7 & 33,1 & 30,7 & 32,4 & 30,7 & 33,1 \\
\hline Batch & $\mathbf{1 4}$ & $\mathbf{1 5}$ & $\mathbf{1 6}$ & $\mathbf{1 7}$ & $\mathbf{1 8}$ & $\mathbf{1 9}$ & $\mathbf{2 0}$ & $\mathbf{2 1}$ & $\mathbf{2 2}$ & $\mathbf{2 3}$ & $\mathbf{2 4}$ & $\mathbf{2 5}$ & $\mathbf{2 6}$ \\
\hline Time [sec] & 30,7 & 33,6 & 30,7 & 36 & 29,9 & 33 & 28,6 & 27 & 27,9 & 27,8 & 29 & 30,6 & 31,7 \\
\hline
\end{tabular}

Table 2. Robotic inspection line data

The histogram below which was constructed with the use of relevant calculations shows that the process is in control. The Gauss distribution curve can be fitted to the histogram. Clearly, the only effects are the random ones.

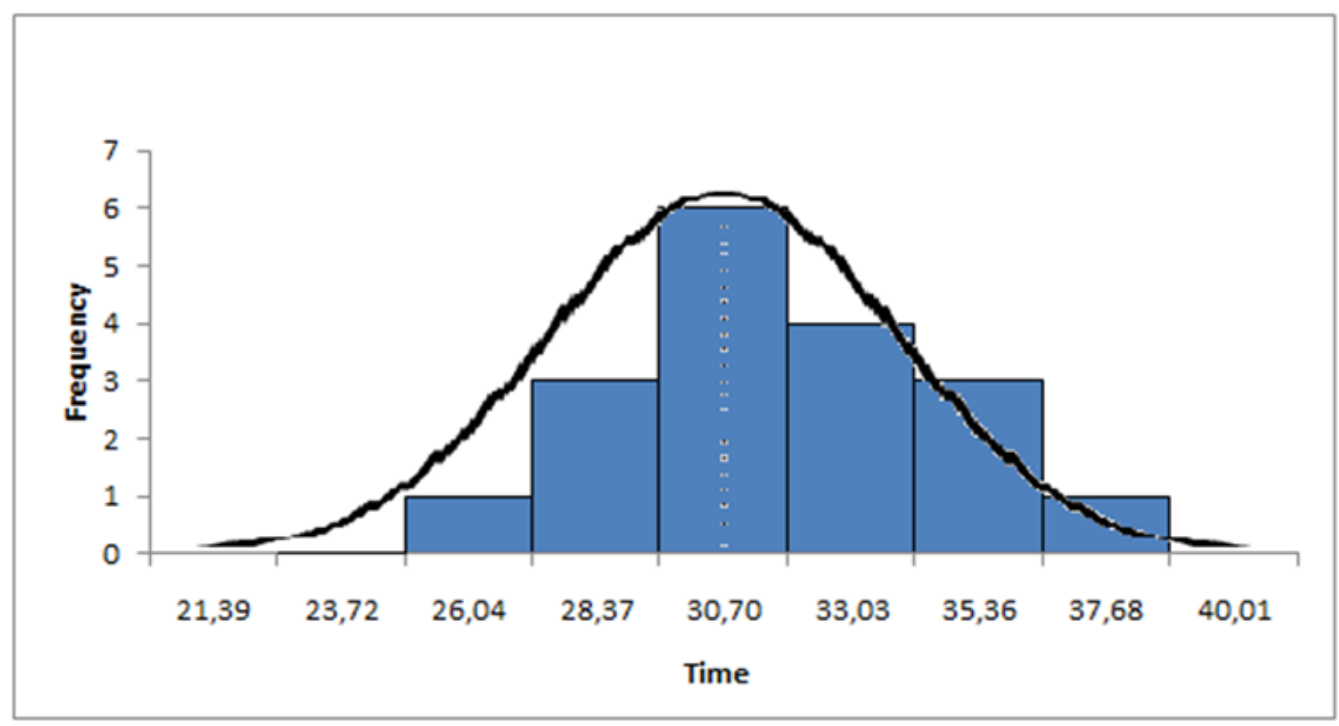

Fig. 4. Histogram, Frequencies of Robotic line 
The assessment criterion is the inspection capability index whose sufficient values for the automotive and aerospace industry are deemed to be 1.67 and higher. The minimum of the index is 2.86 . As $2.86>1.67$, the inspection process can be deemed capable of delivering the desired output.

\section{PFMEA}

\subsection{PFMEA introduction}

In today's industrial production, process risk assessment by means of PFMEA is one of the cornerstones of control processes. The history of FMEA goes back to the 1940s when the U.S. Army sought a technique for eliminating errors in the machines and equipment in use. 1960s saw the first non-military use of this method when NASA (National Aeronautics and Space Administration) began to use FMEA to identify potential risks in Apollo and Gemini programmes. The truly civilian era of risk assessment began 10 years later when the method was adopted by the automotive industry, particularly the Ford company in an attempt to address the low quality of its Ford Pinto model.

PFMEA is a team-based approach to potential risk assessment where the multidisciplinary team is usually led by the engineer who is responsible for the product design. Active involvement of representatives of all areas concerned is expected, including assembly, production, design, testing and others. Once the process and its boundaries have been clearly defined, brainstorming, Ishikawa diagram or other tools are used to identify as many risks as possible which may threaten the process.

These risks are then evaluated according to a consistent method from three aspects: severity of consequences in respect of the customer, occurrence of consequences in respect of the customer and the chance of detection. The RPN (Risk Priority Number) is then calculated. If the internally set value is exceeded, this means that the risk is unacceptable and it is necessary to take measures to reduce it. [2], [4]

\subsection{PFMEA evaluation}

PFMEA and RPN analysis prepared using previous analysis data analysis clearly showed that the replacement of manual inspection by automated process inspection caused significant decrease RPN for all evaluated risks

The company, like many companies in the automotive and aerospace industries, has an internally set RPN acceptance level of 100 . As is clear from the analysis, properly set automation has completely eliminated 5 critical and extremely important points for customer and part safety.

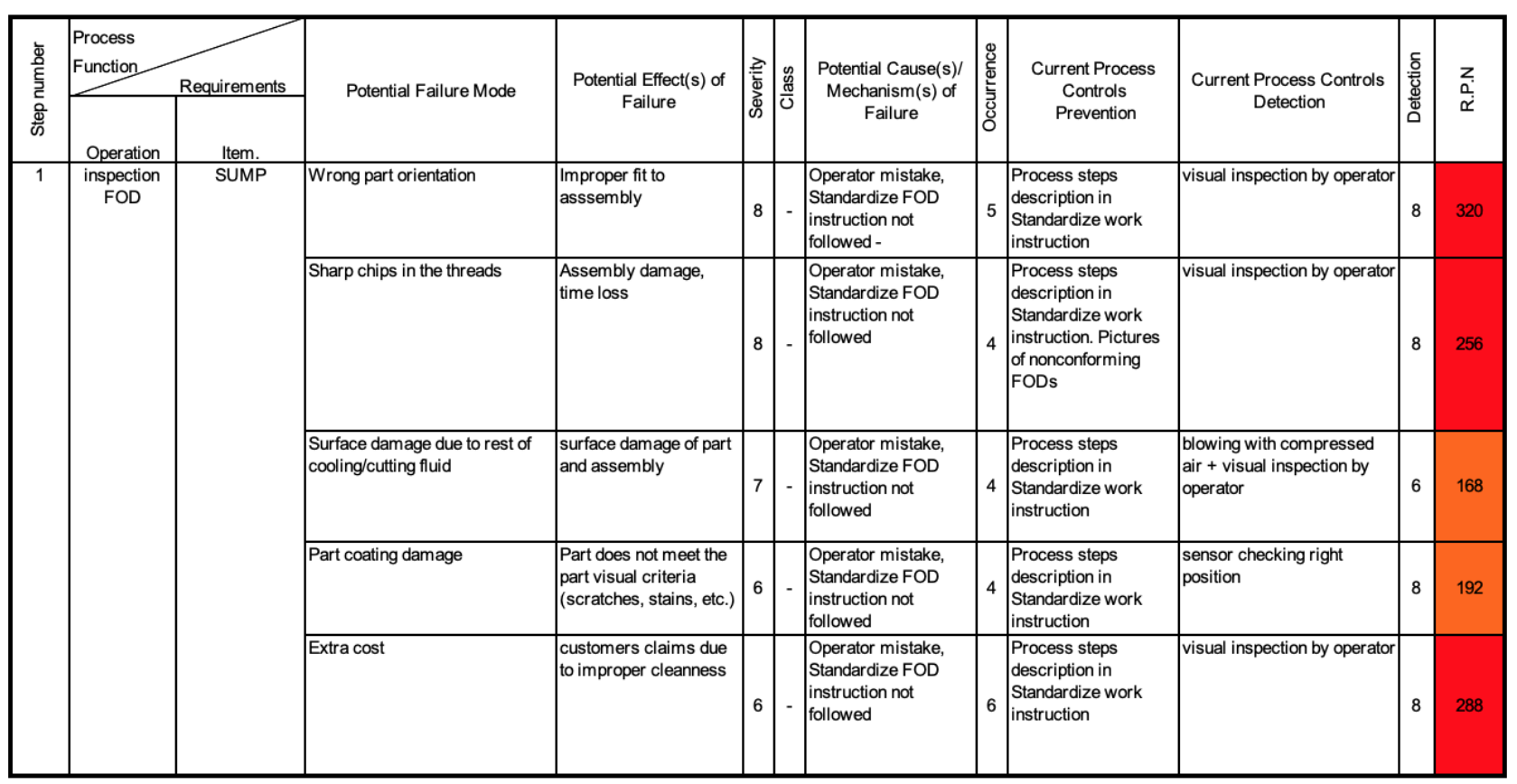

Fig. 5. PFMEA - Manual inspection 


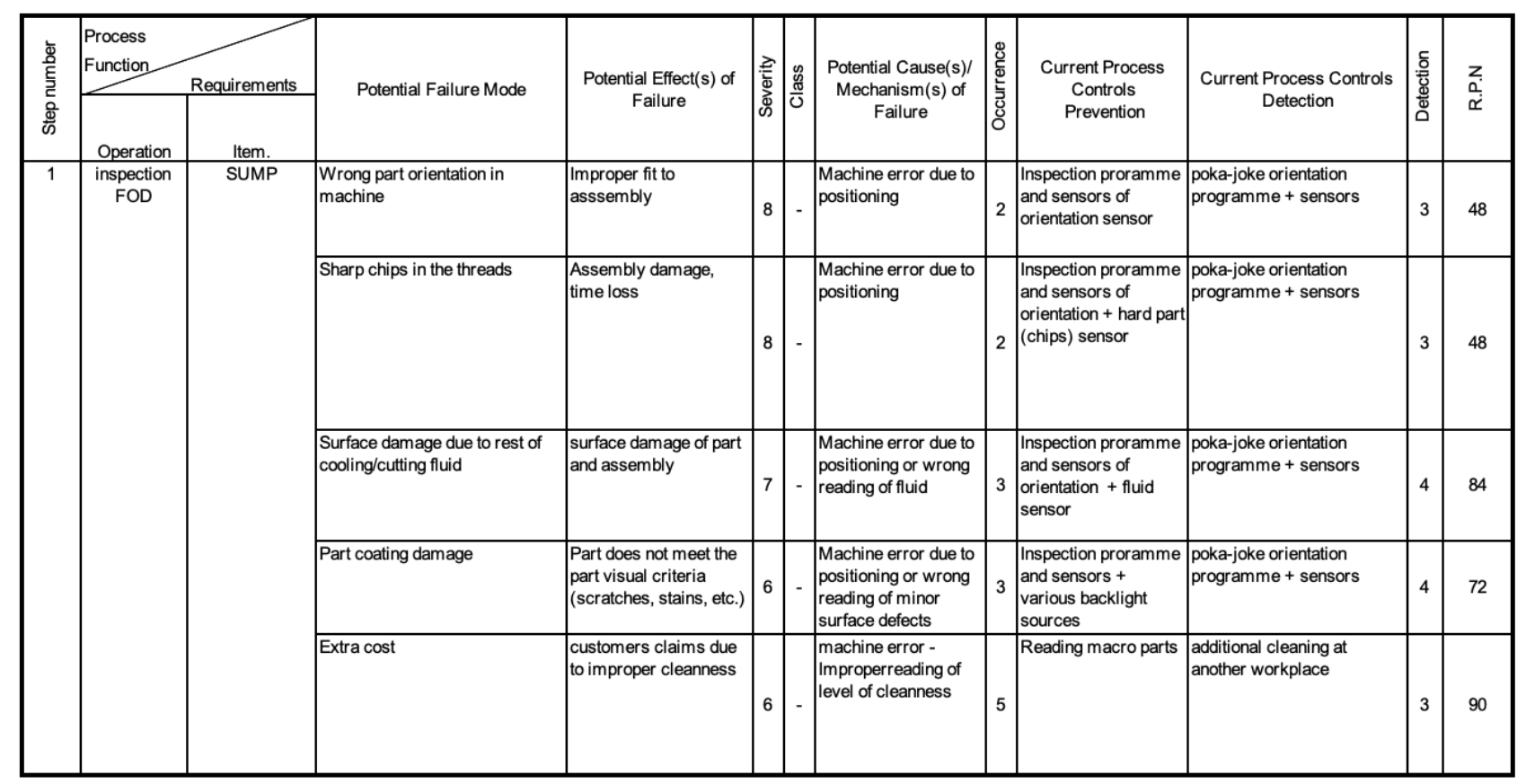

Fig. 6. PFMEA - Robotic inspection

\section{Conclusion}

The motivation for developing this paper was a consideration of the effectiveness of the ever growing trend of Industry 4.0. in the field of final inspection. The experiment chosen for testing was the FOD inspection in a aerospace company. To develop the consideration, real-world inspection data was necessary. Averaged numbers from time measurements were used, each time representing the interval in which one of identical part was inspected. As the times were measured under identical environmental conditions in both the manual and the automated line, they were fit for statistical comparison. The statistical process control (SPC) technique was employed where understanding the process and its limits, elimination of variables and accurate monitoring of processes in both lines was of major importance. It was carried out with the use of tables and graphs in order to detect possible errors and deviations.

Both inspection processes are characterized in a table of measured values which served as basis for constructing histograms with all required features. Results of the manual process analysis showed clearly that it was not in control. Moreover, three rejects were produced as part of the measured batch, leading to financial losses. The median of the manual line inspection time was almost one third higher than in the automated line, leading to appreciable time losses. The fact that the process is not in control results in additional time (and therefore financial) losses. The data from the automated line were processed in an equal manner. Their histogram showed that the process was in control and followed the normal distribution. The process capability was significantly higher than the specified minima.

Subsequently, a multidisciplinary team composed of representatives of the accredited laboratory of the Regional Institute of Technology, the University of West Bohemia in Pilsen, representatives of the final and customer quality department of the world manufacturer of aircraft components. Risk priority number evaluation based on previous analysis data, claims data and final inspection data clearly shows massive risk reduction and all risks have moved below the acceptance limit. Thanks to the achieved and in practice also computationally verified results, deeper cooperation was established in the field of aerospace and evaluation of FOD parameters next year.

\section{Acknowledgments}

The article contribution has been prepared under project SGS-2019-008

\section{References}

[1] Svingerova, M. \& Melichar, (2017). Evaluation of Process Risks in Industry 4.0 Environment, Proceedings of the 28th DAAAM International Symposium, pp.1021-1029, B. Katalinic (Ed.), Published by DAAAM International, ISBN 978-3-902734-11-2, ISSN 1726-9679, Vienna, Austria DOI: 10.2507/28th.daaam.proceedings.142

[2] Banduka, N.; Macuzic, I.; Stojkic, Z.; Bosnjak, I. \& Peronja, I. (2016). Using 80/20 Principle to Improve Decision Making at PFMEA, Proceedings of the 27th DAAAM International Symposium, pp.0487-0492, B. Katalinic (Ed.), Published by DAAAM International, ISBN 978-3-902734- 08-2, ISSN 1726-9679, Vienna, Austria DOI: 10.2507/27th.daaam.proceedings.073 
[3] Markova, P.; Prajova, V.; Homokyova, M. \& Horvathova, M. (2019). Human Factor in Industry 4.0 in Point of View Ergonomics in Slovak Republic, Proceedings of the 30th DAAAM International Symposium, pp.0284-0289, B. Katalinic (Ed.), Published by DAAAM International, ISBN 978-3-902734-22-8, ISSN 1726-9679, Vienna, Au

[4] Skrivanova, N. \& Melichar, M. (2019). The Comparison of Destructive and Non-Destructive Forms of Measurement in the Automotive Industry, Proceedings of the 30th DAAAM International Symposium, pp.0995-1002, B. Katalinic (Ed.), Published by DAAAM International, ISBN 978-3-902734- 22-8, ISSN 1726-9679, Vienna, Austria DOI: 10.2507/30th.daaam.proceedings.138

[5] Poor, P. \& Basl, J. (2018). Czech Republic and Processes of Industry 4.0 Implementation, Proceedings of the 29th DAAAM International Symposium, pp.0454-0459, B. Katalinic (Ed.), Published by DAAAM International, ISBN 978

[6] Brkljac, M. \& Sudarevic, T. (2018). Sharing Economy and „Industry 4.0“ as the Business Environment of Millennial Generation - a Marketing Perspective, Proceedings of the 29th DAAAM International Symposium, pp.1092-1101, B. Katalinic (Ed.), Published by DAAAM International, ISBN 978- 3-902734-20-4, ISSN 1726-9679, Vienna, Austria DOI: $10.2507 / 29$ th.daaam.proceedings. 156

[7] Clares Rodriguez, J. M.; Vazquez Martinez, J. M.; Gomez-Parra, A.; Puerta Morales, F. J. \& Marcos, M. (2016). Experimental Methodology for Evaluating Workpieces Surface Integrity in Dry Turning of Aerospace Alloys, Proceedings of the 26th DAAAM International Symposium, pp.0849-0855, B. Katalinic (Ed.), Published by DAAAM International, ISBN 978-3-902734- 07-5, ISSN 1726-9679, Vienna, Austria DOI:10.2507/26th.daaam.proceedings.118

[8] Kuts, V.; Sarkans, M.; Otto, T. \& Tahemaa, T. (2017). Collaborative Work Between Human And Industrial Robot In Manufacturing By Advanced Safety Monitoring System, Proceedings of the 28th DAAAM International Symposium, pp.0996-1001, B. Katalinic (Ed.), Published by DAAAM International, ISBN 978-3-902734-11-2, ISSN 1726-9679, Vienna, Austria DOI: 10.2507/28th.daaam.proceedings.138 